\title{
Linyit Kömürün Kurutulması için Karbonik Film Teknolojili Yeni Bir Kurutucu Tasarımı
}

\author{
Hasan HACIFAZLIOĞLU ${ }^{1 *}$, Buse BOLAT ${ }^{2}$ \\ ${ }^{1}$ Maden Mühendisliği, Mühendislik Fakültesi, İstanbul Üniversitesi-Cerrahpaşa, İstanbul, Türkiye \\ ${ }^{2}$ Maden Mühendisliği, Mühendislik Fakültesi, İstanbul Üniversitesi-Cerrahpaşa, İstanbul, Türkiye \\ ${ }^{* 1}$ hasanh@istanbul.edu.tr, ${ }^{2}$ busebolat.9701@gmail.com
}

Öz: Endüstriyel ölçekte kömür kurutma ișlemleri için genellikle döner kurutucular tercih edilmektedir. Ancak, döner kurutucuların ilk yatııım ve bakım-onarım maliyetleri oldukça yüksektir. Ayrıca, döner kurutucularda kömürün tutuşma riski de bulunmaktadır. Bu bağlamda, çevre ile dost, ilk yatırım maliyeti düşük ve kömürün tutuşma riski bulunmayan bir kurutma sistemi düşünüldüğ̈̈nde, karbonik film teknolojisi ön plana çıkmaktadır. Karbonik film teknolojisi ile kendiliğinden tutuşma riski olan kömürlerin "düşük sıcaklık kurutması" yapılabilir. Ancak, bu teknolojiyle kurutma yapan herhangi bir kurutucu sistemi henüz mevcut değildir. Bu çalışmanın amacı yeni teknoloji olan "karbonik film 1sıtıcı" ile yeni bir kurutucu tasarımıdır. Deneysel çalışmalar göstermiştir ki, karbonik film teknolojisi ile linyit kömürlerin nemi düşük enerji tüketim değerleriyle giderilebilmektedir. Ancak, bu teknolojinin kurutma süresinin uzun olduğu söylenebilir. Öyle ki, 1 saatlik kurutma işlemi sonunda linyitteki nem \%9 civarında azaltılabilmiştir.

Anahtar kelimeler: Linyit kömür, Kurutma, Karbonik film, Kurutucu tasarımı

\section{Design of A New Dryer With Carbonic Film Technology For Drying Lignite Coal}

\begin{abstract}
Rotary dryers are generally preferred for industrial coal drying processes. However, the initial investment and maintenance-repair costs of rotary dryers are quite high. In addition, there is a risk of coal igniting in rotary dryers. In this context, considering a drying system that is environmentally friendly, has a low initial investment cost and has no risk of ignition of coal, carbonic film technology comes to the fore. With the carbonic film technology, "low-temperature drying" of the coals at risk of self-ignition can be done. However, there is no dryer system drying with this technology yet. The aim of this study is to design a new dryer with the new technology "carbonic film heater". Experimental studies have shown that, with the carbonic film technology, the moisture of lignite coals can be removed with low energy consumption values. However, it can be said that the drying time of this technology is long. So much so that after 1 hour of drying, the moisture in the lignite could be reduced by around $9 \%$.
\end{abstract}

Key words: Lignite coal, Drying, Carbonic film; Dryer design

\section{Giriş}

Ülkemiz linyitlerindeki en önemli safsızlıklardan biri de nemdir. Nem, bazı linyitlerde \%60'lara kadar çıkabilmekte ve kömürün 1sıl değerini düşürmektedir. Kömürlerde giderilen \%1'lik nem kömürün 1sıl değerinde kömür tipine bağlı olarak ortalama 40-60 kcal/kg'lık bir artış sağlamaktadır. Ayrıca nem; nakliye, stoklama ve firınlarda gereksiz yük oluşturmakta ve işlem maliyetlerini arttırmaktadır.

Kömürler, gözenekli yapıları ve içeriğindeki yüksek adsorpsiyon yetenekli kil mineralleri nedeni ile önemli miktarlarda nemi bünyelerinde hapsedebilmektedir. Diğer taraftan, kömürlerin boyutu küçüldükçe birim yüzey alanı artışı nedeni ile nem tutma kapasiteleri de o derece artmaktadır. İnce boyutlu kömürlerde bulunabilecek nem tipleri Şekil 1'de gösterilmiştir. Bu nemlerin büyük bir bölümü (adsorbe yüzey suyu, parçacıklar arası su, kapiler su, adezyon suyu) filtre ve santrifüj gibi çeşitli "susuzlandırma makineleri” ile giderilebilirken, özellikle kömüre kimyasal bağlarla bağlı olan adsorbe bünye suyu sadece termal bir işlem olan "kurutma" yöntemi ile giderilebilir. Kurutma yöntemi ile mevcut tüm nemlerin giderilmesi mümkündür [1].

Kömürler üzerinde yapılan çoğu araştırma göstermiştir ki, özellikle düşük kaliteli kömürler (linyitler) 40-50 ${ }^{\circ} \mathrm{C}$ gibi sıcaklıklarda kendiliğinden yanmaya başlamaktadır [2]. Kömürde $40{ }^{\circ} \mathrm{C}$ 'den sonraki sıcaklıklarda yavaş yavaş oksidasyon başlamakta ve özellikle $70^{\circ} \mathrm{C}^{\prime}$ lik sıcaklıklardan sonra oksidasyon hızı artmaktadır. $\mathrm{Bu}$ oksidasyon ile $1 S 1$ artmakta ve kömürün tutuşma sıcaklığına (düşük kaliteli kömürler için $150-250{ }^{\circ} \mathrm{C}$ ) ulaşması durumunda ise kömür yanmaya başlamaktadır [2-4]. Dolayısıyla, yüksek 1sı üreten kurutucular kömürün

\footnotetext{
* Sorumlu yazar: hasanh@istanbul.edu.tr. Yazarların ORCID Numaras: ${ }^{1}$ iD $0000-0003-1651-7779,{ }^{2}$ iD $0000-0002-5114-2565$
} 
tutuşmasına ve yanmasına neden olabilir. Düşük tutuşma sıcaklığı olan linyit kömürlerin kurutulması için düşük 1S1 üreten kurutucular kullanılması tavsiye edilmektedir.

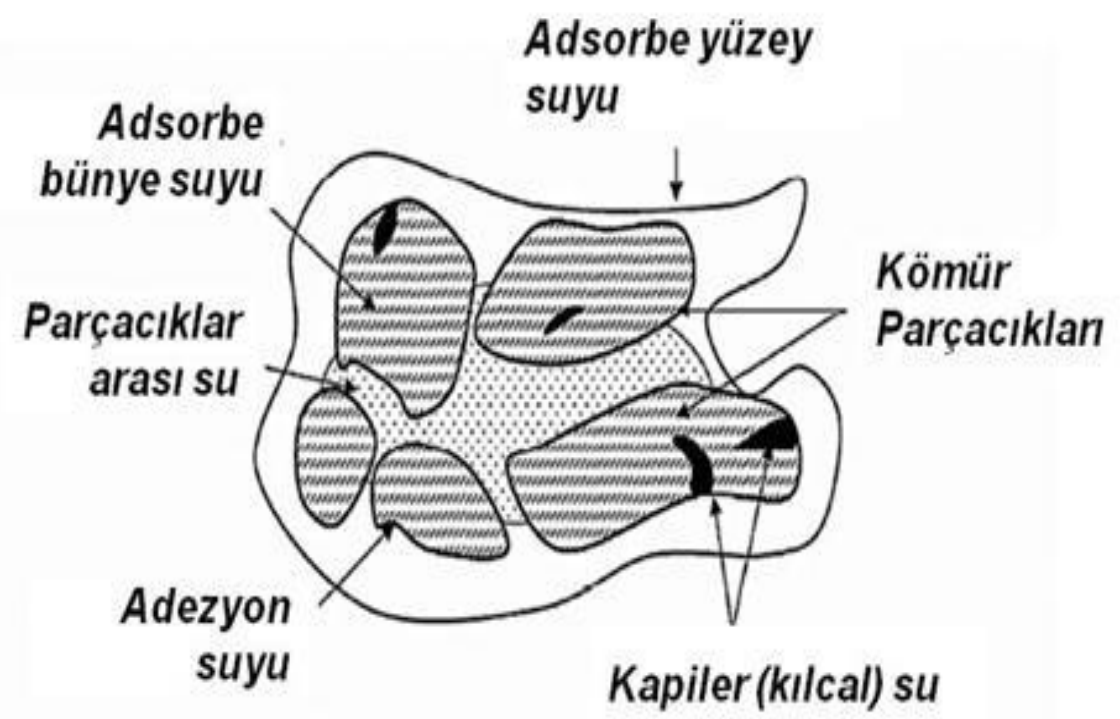

Şekil 1. İnce taneli kömürlerde bulunabilecek nem tipleri

Kurutma, bir malzeme içerisinde bulunan sıvının 1sıl yolla uzaklaştırılması işlemidir. Bu işlem çeşitli yöntemlerle gerçekleştirilebileceği gibi genellikle Termodinamiğin I. Kanunu, enerjinin korunumu ilkesine göre, 1S1 ve kütle transferi yoluyla gerçekleştirilir. Malzemenin herhangi bir yöntemle 1sıtılması sonucunda içeriğindeki sıvı buharlaşmakta ve kuruma işlemi gerçekleşmektedir. Kurutma işleminin temeli, gerekli olan 1sı enerjisi oluşturmaya dayanır. Isı temelde 5 farklı şekilde ortaya çıkarılabilir. Bunlar; kimyasal reaksiyon (örneğin kömür ve doğalgazın yanması gibi), nükleer reaksiyon (örneğin güneşteki reaksiyonlar gibi), öz direnci yüksek telden akım geçirilmesi ile (örneğin rezistanslı 1sıtıcılardaki gibi), mekanik olarak (malzemeye sürtünme veya basınç uygulayarak) ve elektromanyetik ışınım ile yani radyasyon yolu ile de (mikrodalga firınlarda olduğu gibi) 1sı oluşturulabilir.

Bir kurutma işlemindeki 1Sı transferi, kondüksiyon, konveksiyon ve radyasyon yoluyla yapılabilir. Klasik kömür kurutucularında kondüksiyon ve konveksiyonla 1sı transferi gerçekleşirken, son yıllarda özellikle düşük enerji tüketimleri nedeniyle mikrodalga, kızılötesi ışın, ultraviyole, radyo dalgası gibi radyasyon yoluyla ısıtma çalışmalarına ağırlık verilmiştir. Isının radyasyon yolu ile transferinde maddesel bir ortama ihtiyaç duyulmaz.

Bir çeşit radyasyon olan kızılötesi 1şınım, etraflarındaki havayı 1sıtmadan sadece 1şı geçirmeyen cisimleri 1sıtmaktadır. Kızılötesi 1sıtma; boya kurutma, plastik üretimi, tavlama ve meyve kurutma gibi alanlarda kullanılmaktadır. Malzemenin karakteristiğine uygun kızılötesi frekans seçimi enerji verimliliğini de etkilemektedir. Temelde üç tip kızıl ötesi ışın olup; bunlar, kısa, uzun ve orta dalga kızılötesi ışınlardır. Aralarındaki temel fark radyasyonun işleyebilme derinliğidir. Uzun dalgalar malzemenin sadece yüzeyini isıtırken, kısa dalgalar malzemenin içine kadar işler. Orta dalga kızılötesi ışınlar ise uzun ve kısa dalgaların işleyebildiği derinliğin yarısı kadar bir derinliğe işleyebilir [5-13]. Karbonik film, uzun kızılötesi ışın yayan yeni nesil bir ısıtıcı tipidir. Film içerisinde bulunan karbon nano partiküller yardımıyla radyasyon ısısı oluşturulur ve yüzey 1sıtılır.

$\mathrm{Bu}$ çalışmada, uzun kızılötesi 1şın yayan karbonik film teknolojisi ile linyit kömürü düşük sicaklık kurutmasına tabi tutulmuş ve bu karbonik filmle yeni teknoloji bir kurutucu tasarımı yapılmıştır.

\section{Karbonik Film Teknolojisi}

Karbonik filmdeki 1sı üretim mekanizması, elektromanyetik ışınım, yani radyasyon yolu ile sağlanır. Karbonik 1sitıcı film, iletken olmayan ve yanmayan filme 1sıtıcı karbon tabaka ve kirlilik önleyici tabakanın işlenmesi, bakır şerit ile elektrotun hazırlanması sonrası PET film ile lamine işleminin yapılması ile oluşturulan son teknoloji yassı bir uzak kızılötesi (FIR) 1sıtıcıdır. Filmin içinde 1sıtma teli, ısıtma kablosu veya rezistans 
bulunmaz. Şekil 2'den görüleceği üzere, temel hammaddesi karbon, gümüş ve bakırdır. Isı kaynağı ortada duran çok ince siyah nano karbon bir tabakadır. Karbon tabakaya verilen elektrik enerjisi ile uzak kızılötesi ışınlar yayılmakta ve film ısınmaktadır. Karbon ısıtıcı filmin üretmiş olduğu uzak kızılötesi 1şınım, 5.6-1000 mikron arasındaki dalga boylarını içeren ışınlardır. Bu ışınlar güneş ışınları, insan vücudu, metaller ve bazı mineraller tarafindan da saçılabilmektedir [12].

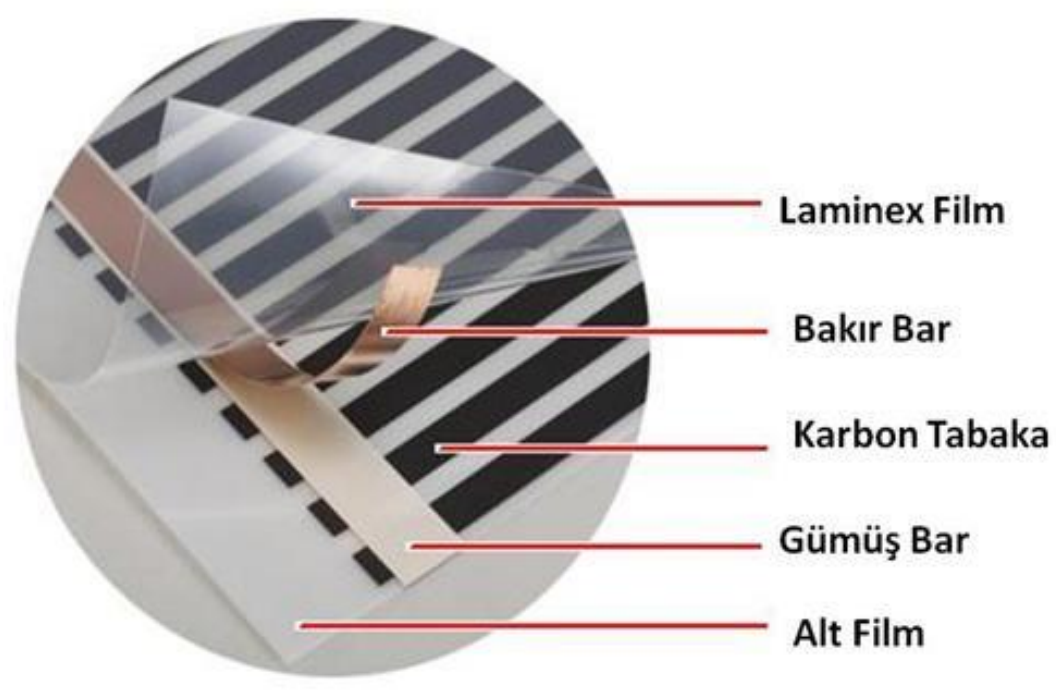

Şekil 2. Karbonik ısıtıcı filmin ısıtma mekanizması ve iç yapısı

Isıtıcı filmin kalitesini kullanılan karbon, gümüș ve bakır tabakaların yapıştırılma ve rezistans kalitesi ile nano partiküllerin akışkanlığı belirler. Şekil 3'de görüldüğü üzere, film çok sayıda katmandan oluşur. Filmin toplam kalınlığ 0.5 mm'dir. Filmlerin boyu 100 m'ye kadar, enleri ise $1 \mathrm{~m}$ 'ye kadar üretilebilmektedir. Şimdiki teknoloji ile karbon filmlerin yüzey sıcaklıkları $60{ }^{\circ} \mathrm{C}$ kadar çıkabilmektedir. Özel üretim filmlerle daha yüksek sıcaklıklara ulaşılabileceği firma tarafından belirtilmiştir. Ayrıca film ısıtıcının dış tabakası olan PET, özel bir ürün olup hava ile temas etmeyecek şekilde izolasyonu sağlamakta ve isıtıcı filmi yatay ya da dikey zeminlerde kullanmaya olanak sağlamaktadır. Bu PET tabakası değiştirilerek daha sağlam, aşınmaya dayanıklı yüzeyler elde edilebilir [13]. Karbonik filmlerin başlıca avantajları, ilk yatırım maliyetinin ve işletme maliyetinin düşük olmasıdır. Ayrıca, hızlı ısınma yeteneğine sahip olması, işlem kolaylığı sağlamaktadır.

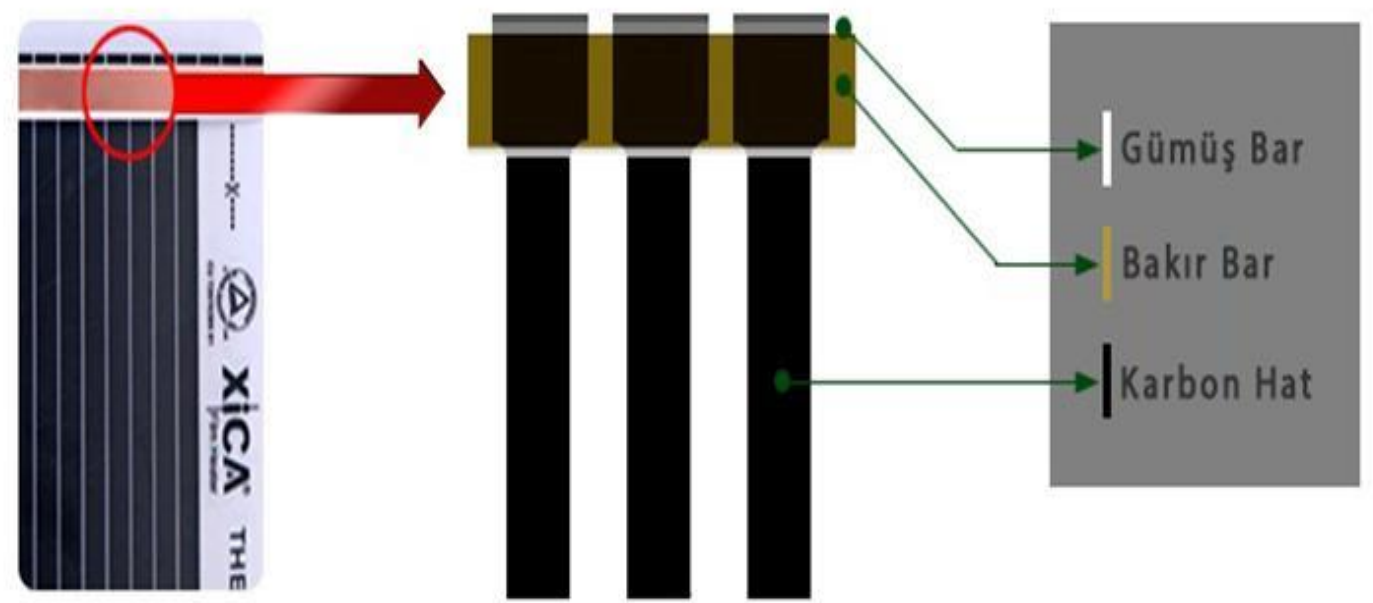

Şekil 3. Karbonik film ısıtıcıdaki gümüş, bakır bar ve nano karbon hattının görüntüsü 


\section{Deneysel Çalışmalar}

\subsection{Linyit Kömür Numunesinin Özellikleri}

Deneysel çalışmalarda kullanılan linyit kömür numunesi Akdeniz bölgesinde faaliyet gösteren bir kömür ocağından alınmıştır. Açık işletme yöntemi ile işletilen bu ocakta kömürün havanın durumuna bağlı olarak \%45 ile $\% 55$ oranında nem içerebilmektedir. Bu kömürler primer ve sekonder kırıcıdan geçirilerek $10 \mathrm{~mm}$ 'nin altına kırıldıktan sonra termik santralde akışkan yataklı bir kazanda yakılmakta ve elektrik enerjisi üretimi için kullanılmaktadır.

Özellikle \%50 nemin üzerindeki kömürlerin yakılmasında akışkan yatakta çeşitli problemler (korozyon, cüruf oluşumu vb) meydana gelmekte ve bunun sonucunda hem kazan hem de 1sıl verim düşmektedir. Bu durum elektrik üretim kapasitesini olumsuz yönde etkilemektedir. Bu bağlamda, özellikle sonbahar ve kış aylarında nemin yüksek olması nedeni ile kabarcıklı akışkan yataklı kazanın önüne ekonomik bir kurutucu konulması planlanmaktadır. Endüstriyel ölçekte genellikle kurutma işlemi döner kurutucularla yapılmaktadır. Ancak, döner kurutucuların ilk yatırım, bakım-onarım ve işletim maliyetleri oldukça yüksektir. Ayrıca, bu kurutucuda kömür yakıldığı için sera gazı emisyonları oluşmakta ve çevreyi kirletmektedir.

Söz konusu santralde döner kurutucu kullanılması durumunda yakıt hazırlama prosesinin akım şeması Şekil 4'de gösterildiği gibi olacaktır. Deneysel çalışmalarda kullanılacak olan kömür numunesi döner kurutucunun girişinden alınmıştır. Bu kömür numunesin kısa kimyasal ve 1sıl analizi Tablo 1'de verilmiştir. Tablo 1'e göre kömür orijinal bazda $\% 51.81$ nem içermekte ve brüt 1 sıl değeri $1537 \mathrm{kcal} / \mathrm{kg}$ gelmektedir. Bu kömürün tamamen kurutulması durumunda ise brüt ısıl değer $3189 \mathrm{kcal} / \mathrm{kg}$ 'a kadar yükselmektedir.

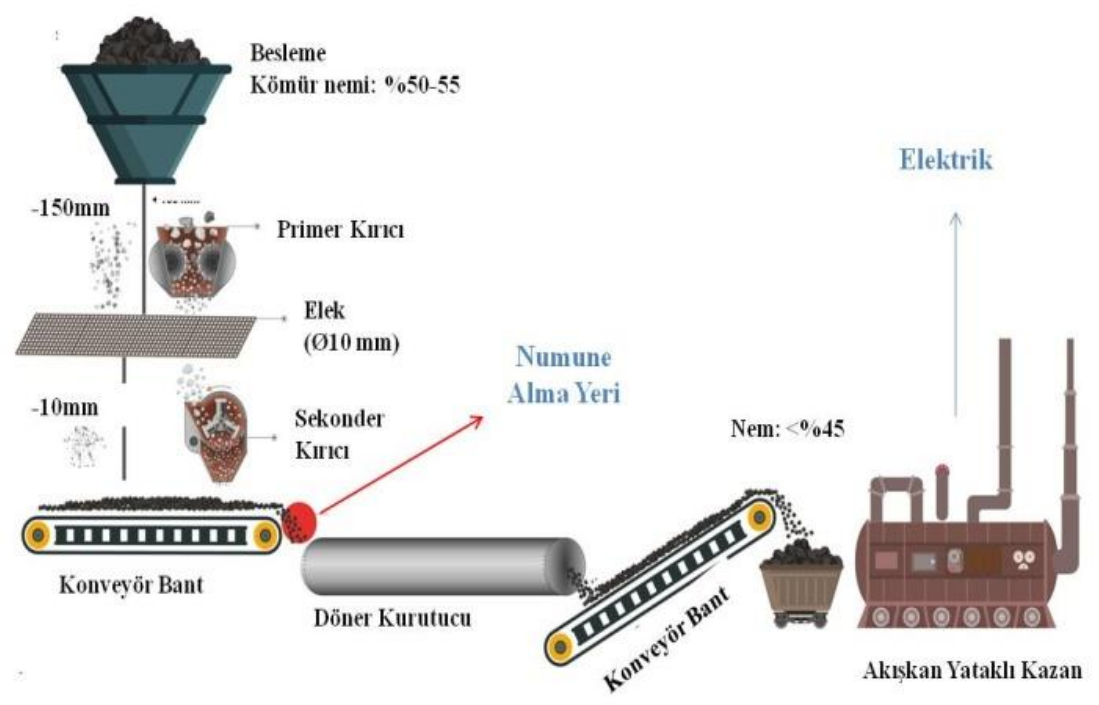

Şekil 4. Döner kurutuculu termik santral yakıtı hazırlama prosesi

Tablo 1. Numunenin kimyasal ve 1 sıl analiz sonuçları

\begin{tabular}{|c|c|c|}
\hline İçerik & $\begin{array}{c}\text { Orijinal } \\
\text { Kömürde }\end{array}$ & Kuru Kömürde \\
\hline Toplam Nem (\%) & 51.81 & 0.00 \\
\hline Kül (\%) & 21.96 & 45.58 \\
\hline Uçucu Madde (\%) & 19.53 & 40.52 \\
\hline Toplam Kükürt (\%) & 1.96 & 4.06 \\
\hline Sabit Karbon (\%) & 18.36 & 38.09 \\
\hline $\begin{array}{c}\text { Brüt Isıl Değer } \\
\text { (kcal/kg) }\end{array}$ & 1537 & 3189 \\
\hline \multicolumn{2}{|l}{} \\
\hline
\end{tabular}


Termik santraldeki akışkan yataklı kazanın tasarım parametreleri brüt $1600-2000 \mathrm{kcal} / \mathrm{kg}$ 'lık kömürün yakılması için planlanmış olup, kömürün neminin \%100 giderilmesinin ve kalorisinin $3189 \mathrm{kcal} / \mathrm{kg}$ 'a yükseltilmesinin hiçbir anlamı yoktur. Bu kömürden \%1'lik nem giderimi ile 1 sıl değerinde yaklaşı $32 \mathrm{kcal} / \mathrm{kg}$ bir artış sağlanmaktadır. \%10 nem giderilmesi durumunda ise orijinal bazda kömürün brüt 1sıl değeri hesaplanırsa; teorik olarak $1537+(32 \times 10)=1857 \mathrm{kcal} / \mathrm{kg}$ bulunur. Bulunan bu isl değerli $(1857 \mathrm{kcal} / \mathrm{kg})$ kömürün yakılması ile akışkan yataklı kazanın ihtiyacı olan optimum kömür elde edilmiş olur. Kurutma maliyetleri de düşünüldüğünde kömürden $\% 5$ ile $\% 10$ aralığında bir nem giderimi termik santral verimliliğinin optimize edilmesi açısından yeterli olacaktır.

\subsection{Karbonik Filmli Deney Düzeneği ve Yöntem}

Yukarıdaki bilgiler ışığında kömür numunesinden \%5-10 aralığında bir nem giderimi yeterli gözükmektedir. $\mathrm{Bu}$ nem gideriminin sağlanması için, ilk yatırım maliyeti düşük, kömürün kendiliğinden yanmasına sebebiyet vermeyecek, çevre dostu yeni teknoloji bir kurutucu tasarımı planlanmıştır. Bu tasarım için özellikle son yıllarda evlerin 1sıtılması amaciyla yaygın olarak kullanılmaya başlayan karbonik film 1sıtma teknolojisinden faydalanılacaktır. Şekil 5'de gösterilen RexVa firmasının XICA karbonik ısıtma filmleri kullanılarak Şekil 6'daki deneysel ölçekli kurutucu tasarlanmıştır.

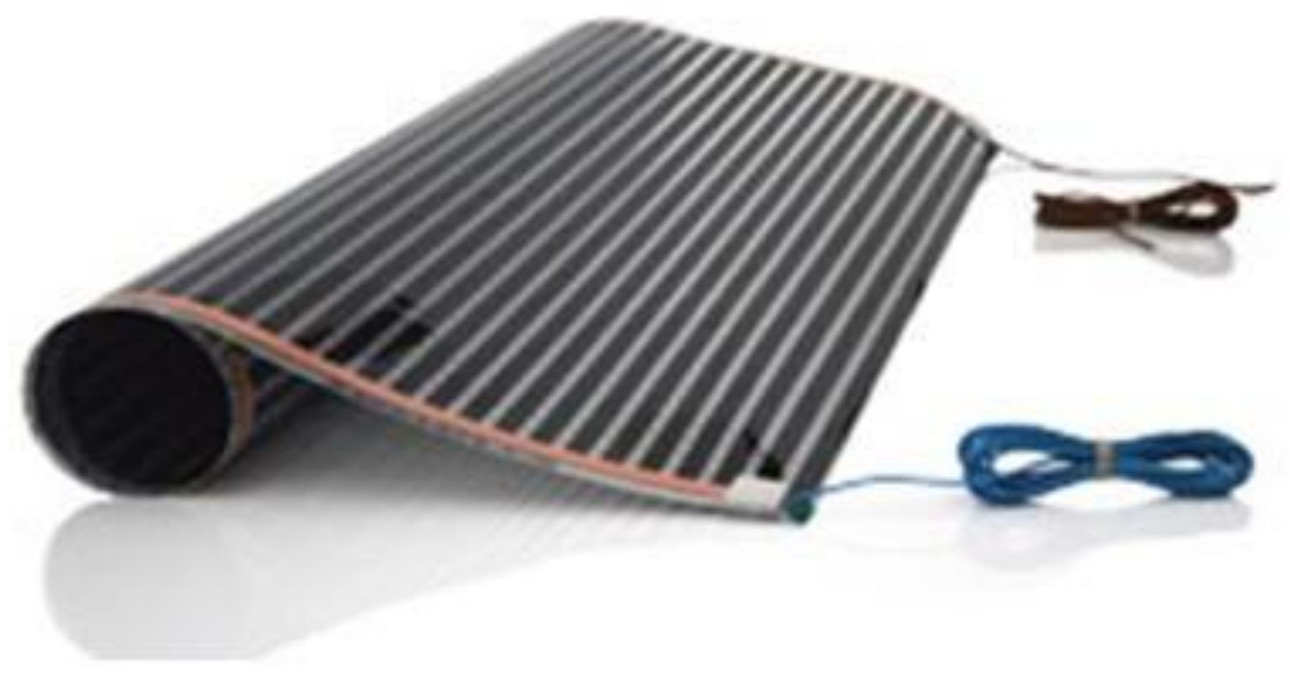

Şekil 5. Kurutucu tasarımında kullanılan ısıtıcı film ve elektrik bağlantısı

Şekil 3.3'de gösterilen deneysel ölçekli kurutucuda kullanılan karbonik film $0.25 \times 0.50 \mathrm{~m}$ ölçülerinde ve toplamda $0.1 \mathrm{~m}^{2}$ lik etkin bir kurutma alanına sahiptir. Karbonik filmin çektiği güç 30 Watt yani $0.003 \mathrm{kWh}$ 'dır. Buna göre karbonik filmin çektiği akım (I) ve oluşturduğu direnç (R) aşağıdaki formüllerle hesaplanırsa:

$\mathrm{W}=\mathrm{V} \times \mathrm{I}$

Denklem 1'den; 30=220 x I, I=0.136 Amper bulunur.

$\mathrm{V}=\mathrm{I} \times \mathrm{R}$

Denklem 2'den karbonik filmin oluşturduğu direnç hesaplanırsa; 220=0.136 x R, R=1617.647 Ohm'luk bir direnç bulunur. Burada, $\mathrm{W}=$ Güç (Watt), $\mathrm{V}=$ Gerilim (Volt), I=Akım (Amper) ve R=Direnç (Ohm)'dur. 


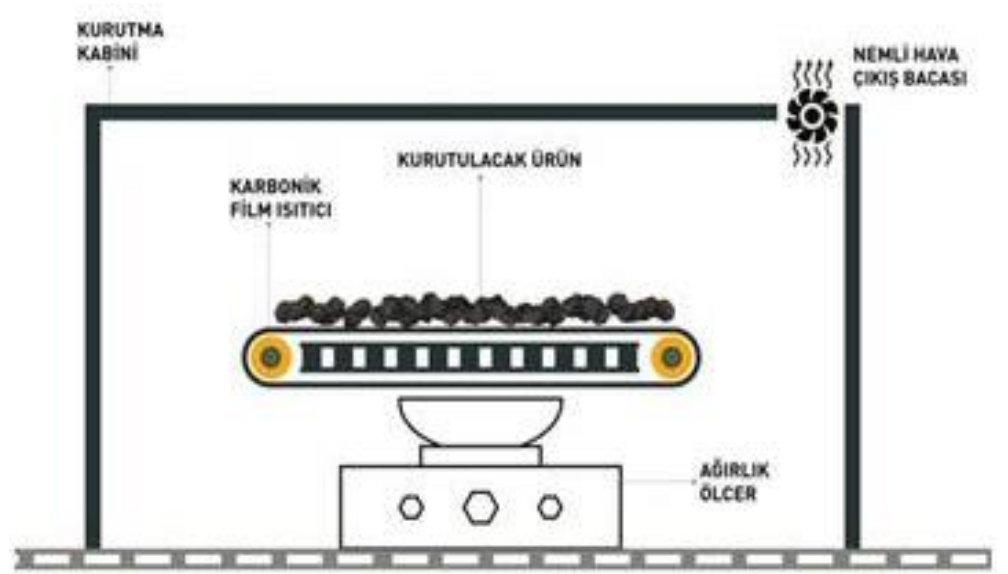

Şekil 6. Karbonik filmli kurutma deney düzeneği

Karbonik film üzerine belli bir yükseklikte boyutu -10 mm olan kömür konulmakta ve filmin altında bulunan hassas teraziden zamana bağlı olarak kömürün ağırlık kaybı tespit edilmektedir. Kurutma deney düzeneğinde yapılan ön incelemelerde, karbonik filmin çektiği güç ya da kurutma isısının kontrol edilemeyeceği saptanmıştır. Karbonik filmin çektiği güç sabit olup, 30 Watt'tır. Kömürün kurutulduğu yüzeyin sıcaklığı ise $50-55^{\circ} \mathrm{C}$ aralığında değişkenlik göstermektedir. Mevcut deney düzeneğinde değiştirilebilecek tek parametre kurutulacak olan kömürün yüksekliğidir. Gerçekten de bu parametrenin oldukça önemli etkilere sahip olduğu deney sonuçlardan da görülmüştür. Karbonik film üzerinde kömürün yüksekliği $10 \mathrm{~mm}, 20 \mathrm{~mm}$ ve $30 \mathrm{~mm}$ olacak şekilde ayrı ayrı deneyler yapılmıştır (Şekil 7). $10 \mathrm{~mm}$ kömür yüksekliğinde kömürün toplam ağırlığı 600 gr iken, $20 \mathrm{~mm}$ yükseklikte 1200 gr, 30 mm yükseklikte ise 1800 gr tartılmıştır. Karbonik film teknolojisi ile kurutma yapılırken çekilmiş olan termal kamera görüntüsü Şekil 8'de verilmiştir.
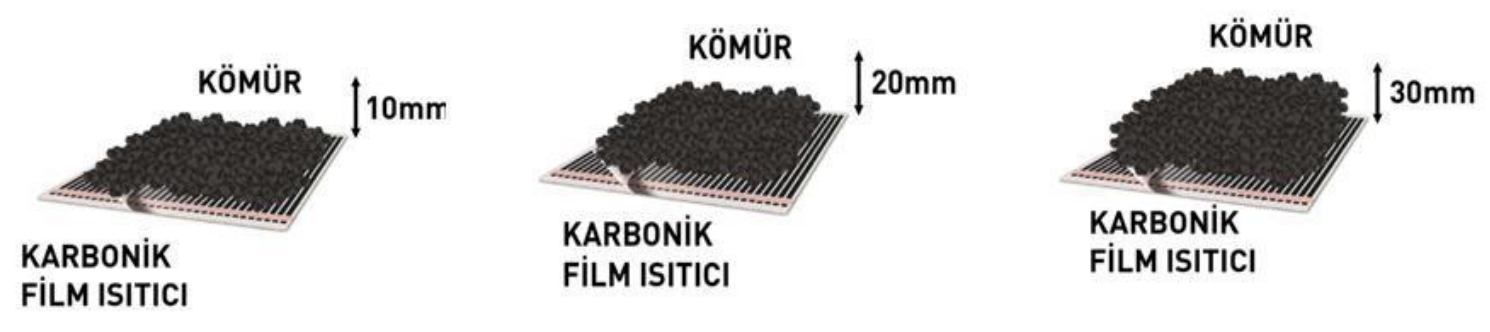

Şekil 7. Karbonik film üzerinde farklı yükseklikteki kömürlerin görüntüsü

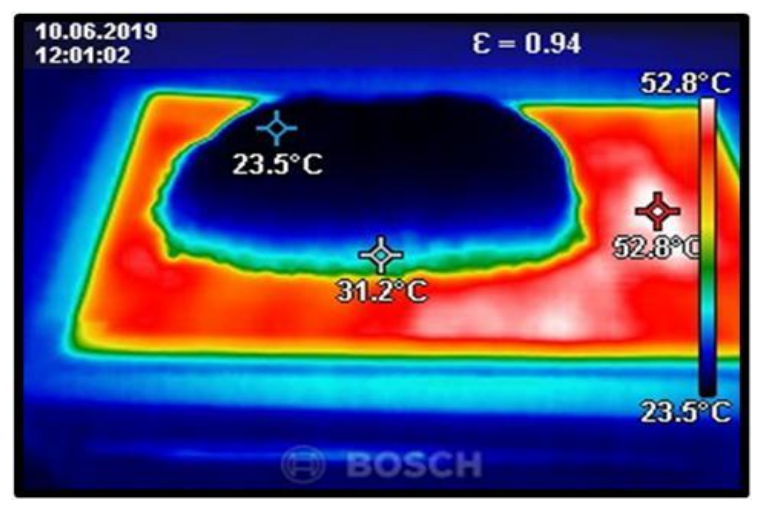

Şekil 8. Kurutma deney düzeneğinin termal kamera görüntüsü 


\section{Deney Sonuçları ve Değerlendirme}

Kurutma süresine bağlı olarak kömürde kalan nem miktarları Şekil 9'da gösterilmiştir. Bu sonuçlara göre, karbonik film ısıtıcı üzerinde $10 \mathrm{~mm}$ yüksekliğinde kömür kurutması yapıldığı zaman 60'ıncı dakikanın sonunda kömürde kalan nem miktarı \%42.80 iken, 20 mm kömür yüksekliğinde kalan nem $\% 47.35,30 \mathrm{~mm}$ yükseklikte ise \%49.30 bulunmuştur. Karbonik film üzerinde kurutulan kömürün yüksekliği arttıkça kömürün içinde kalan nem miktarı da artmaktadır. Başka bir deyişe, kömürden giderilen nem miktarı karbonik film üzerindeki kömür yüksekliği ile ters orantılıdır. Bu durum Şekil 10'dan açıkça görülmektedir. Sirasıyla, 10, 20 ve $30 \mathrm{~mm}$ olan kömür yüksekliklerinde kurutma yapıldığında, 60'ıncı dakikanın sonunda giderilen nem miktarları sirasıyla $\% 9.01$, $\% 4.46$ ve $\% 2.51$ bulunmuştur.

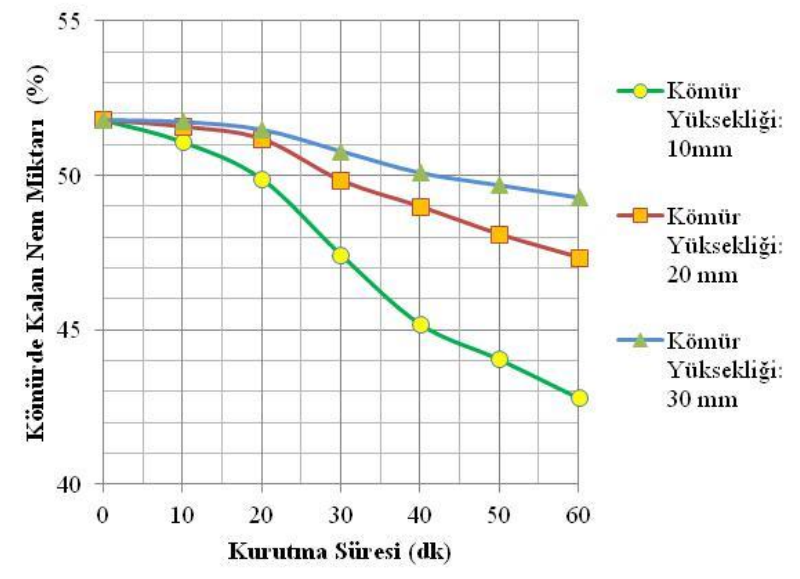

Şekil 9. Kurutma süresine bağlı olarak kömürde kalan nem miktarı

Karbonik film üzerinde kurutulan kömürün yüksekliği önemli bir işletim parametresidir. Öyle ki, yüksekliğin çok fazla olması durumunda kurutma verimi azalmakta ve daha fazla güç ile daha az miktarda su giderimi sağlanmaktadır. Şekil 11 incelendiği zaman, 20 Watt'llk bir enerji ile $10 \mathrm{~mm}$ yüksekliğindeki kömürden $39.66 \mathrm{gr}$ su giderilmişken, kömür yüksekliği 30 mm'ye çıkarıldığında su giderimi 30.78 gr’a düşmüsstür. Bu durumu destekleyen sonuçlar Şekil 12'de verilen nem giderimi-enerji tüketiminden de açıkça görülmektedir. 20 Watt'llk bir enerji ile; $30 \mathrm{~mm}$ yüksekliğindeki kömürden giderilen nem miktarı $\% 1.71$ iken, $10 \mathrm{~mm}$ yüksekliğindeki kömürden giderilen nem miktarı \%6.61 bulunmuştur. Tabaka kalınlığıyla nem giderimi arasında ters bir orantı söz konusudur.

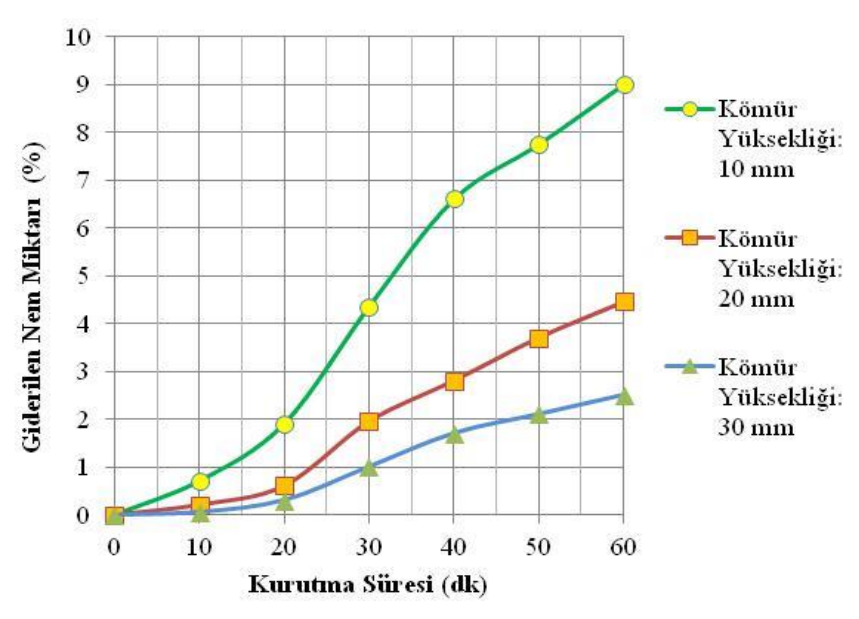

Şekil 10. Kurutma süresine bağlı olarak giderilen nem miktarı 


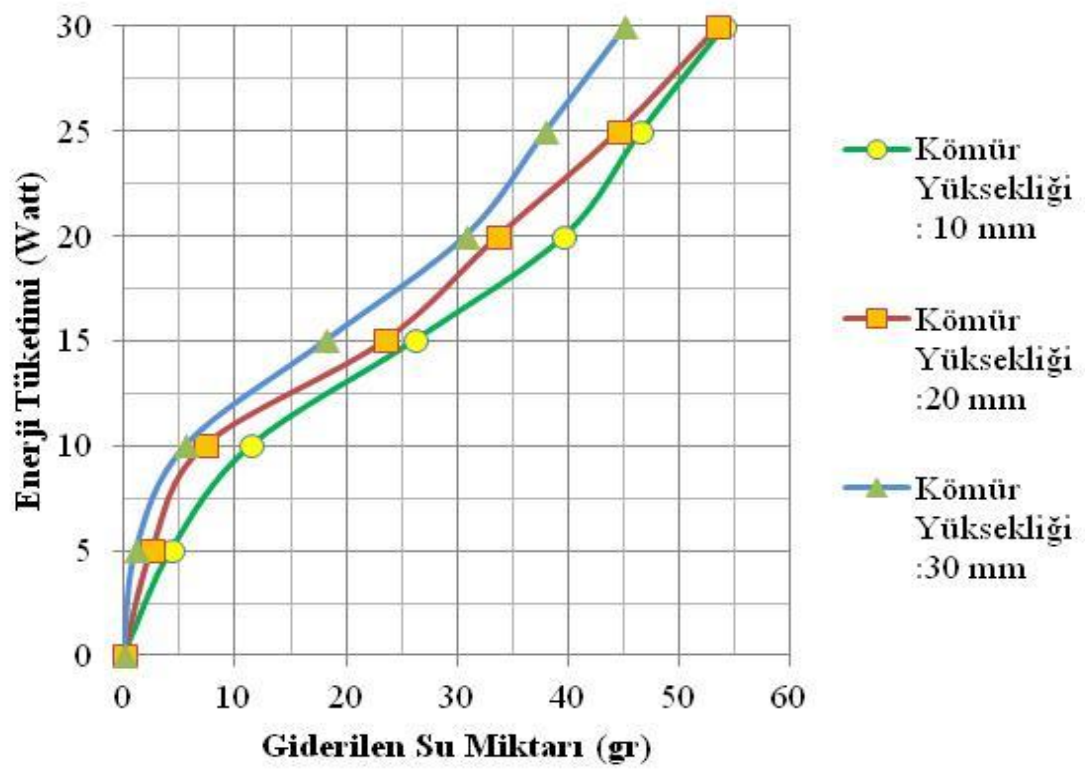

Şekil 11. Giderilen su miktarına bağlı olarak tüketilen enerji miktarları

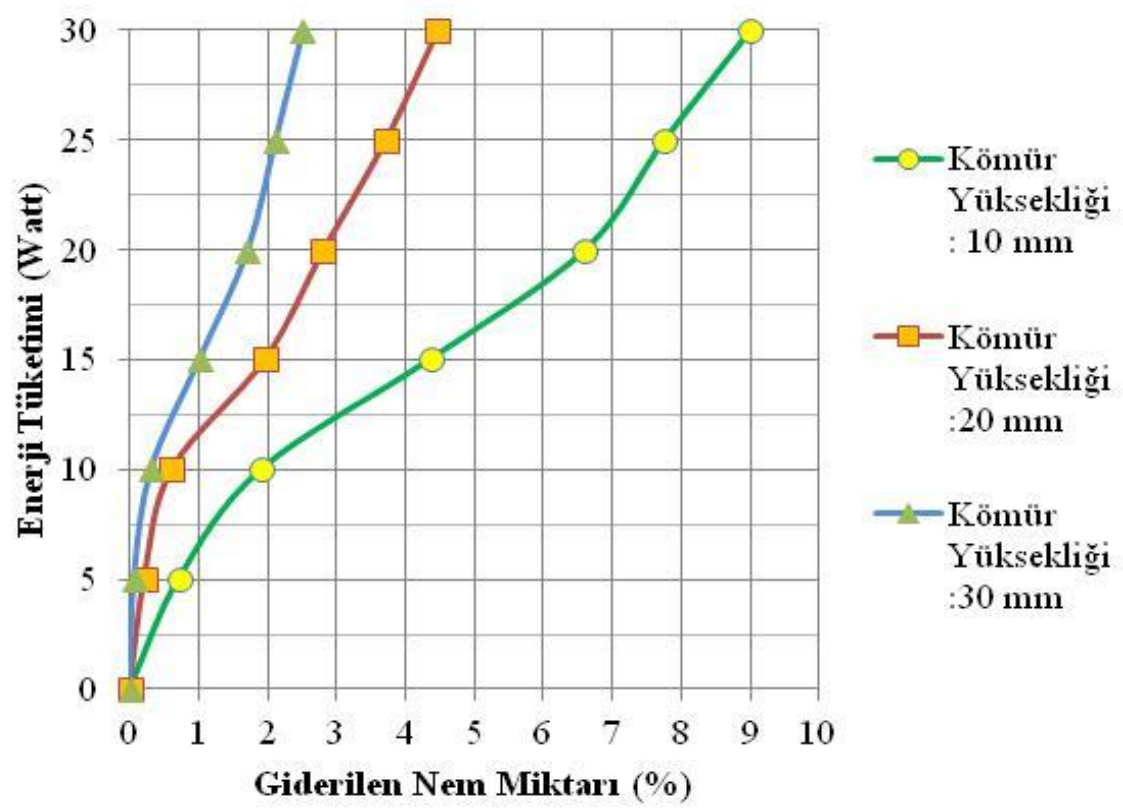

Şekil 12. Giderilen nem miktarına bağlı olarak tüketilen enerji miktarları

Şekil 13'de karbonik film teknolojisi ile kurutma işleminin termal kamera görüntüsü verilmiştir. Kurutulan kömür tabakası alt kısımdan ısınmaya başlamakta ve yukarıya doğru buhar çıkışı olmaktadır. Kömür tabaka kalınlığının artmasıyla üst kısımlar daha serin kalmakta ve üst kısımda kurutma verimi düşmektedir. Ayrıca nemli hava yukarıya doğru yükseldiği için üst kısımların nem içeriği de artmaktadır. Şekil 13'den görülebileceği gibi, 30 mm kömür yüksekliğinde en üst kısmın yüzey sıcaklığ $123.5^{\circ} \mathrm{C}$ 'ye kadar düşmüştür. Oysa, karbonik film yüzeyi $53{ }^{\circ} \mathrm{C}$ ve kömür-film temas yüzeyinde (buharlaşmanın en yoğun olduğu yüzeyde) ölçülen sıcaklık değeri ise 33 ${ }^{0} \mathrm{C}^{\prime}$ dir. 

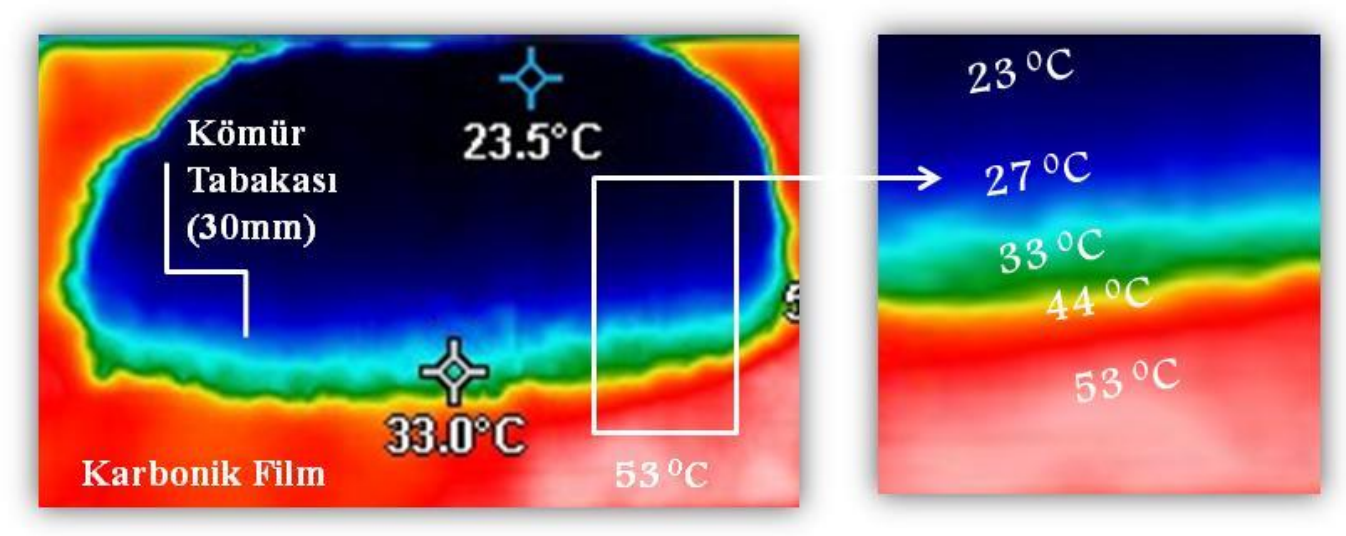

Şekil 13. Karbonik film üzerinde kurutulan kömürün termal kamera görüntüsü

Yukarıdaki veriler 1şığında, karbonik film teknolojisi ile tasarlanması öngörülen kurutucu tipi Şekil 14'de gösterilmiştir. CDC yani "Carbonic Dry Cycle" olarak adlandırılan bu kurutucuda, çentikli bir bant konveyörün üzeri karbonik 1sıtıcı film ile kaplanmakta ve bu film üzerinde hareket halindeki ince $(<10 \mathrm{~mm}) \mathrm{kömür}$ kurutulmaktadır. Isı kaybının minimize edilmesi ve kurutma sıcaklığının daha da arttırılması için çentikli bant konveyör hattı boylu boyunca bir kabinle kapatılmıştır. Yoğuşmanın önlenmesi için kabine yeterli sayıda nem atıcı fanlı bacalar eklenmiştir. Kurutulacak malzeme, hızı ayarlanabilen çentikli bant konveyör üzerinde yavaşça titreştirilerek ve bu esnada karışarak ilerlerken kurutma sağlanmaktadır. \%100 Türk tasarımı olan bu kurutucunun en önemli avantajı hem nakliye hem de kurutmayı aynı anda temiz bir enerji kaynağı ile yani elektrik enerjisi ile yapabilmesidir. Bu tasarım, özellikle kömür ocağından termik santrallere bant konveyör ile taşınan kömürün taşınma esnasında kurutulması için tasarlanmıştır.

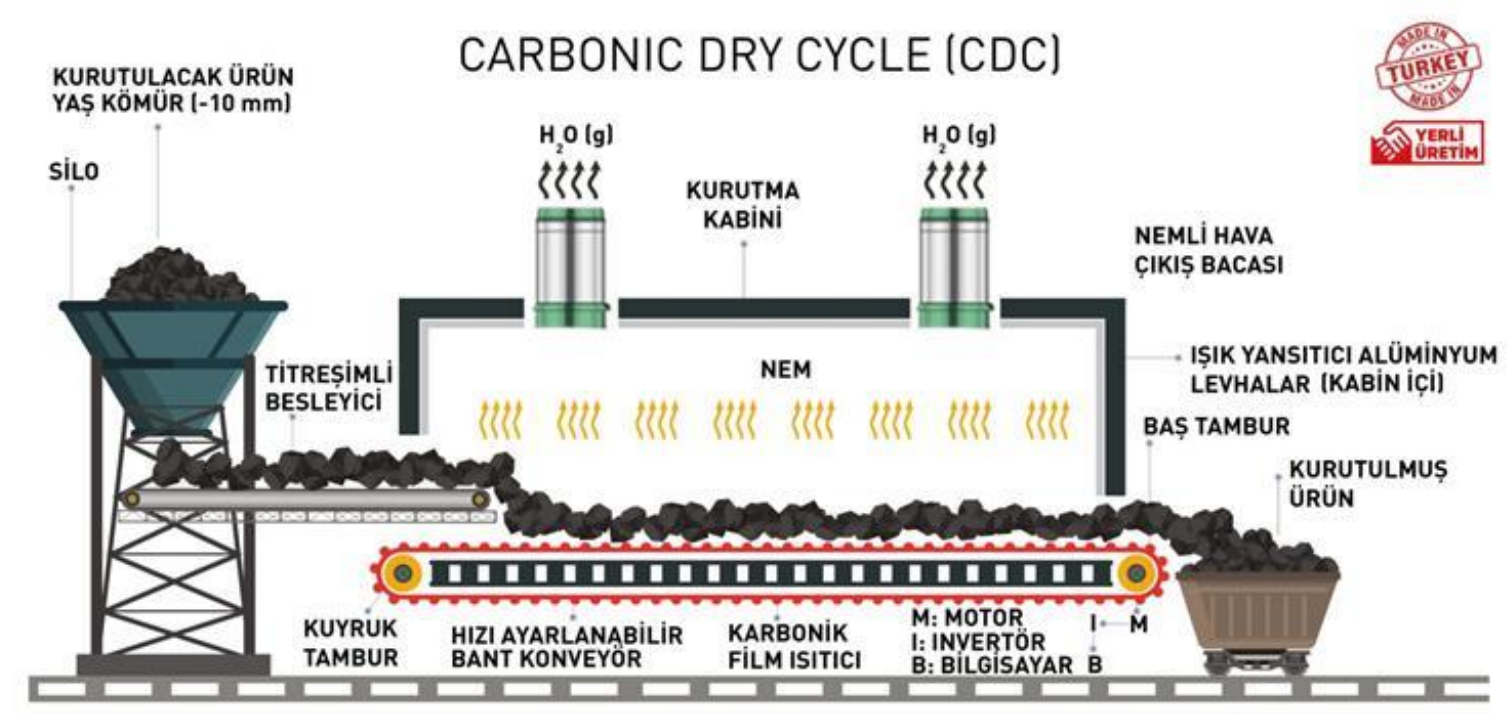

Şekil 14. Endüstriyel ölçekte tasarlanması öngörülen karbonik film 1sıtıcılı kurutucu (CDC)

\section{Tartışma ve Sonuc}

Linyit kömürlerin kendiliğinden yanmaya yatkın olması nedeni ile düşük sıcaklıklarda $\left(<100^{\circ} \mathrm{C}\right)$ kurutulması gerekmektedir. Düşük sıcaklık kurutmasının en önemli dezavantajı uzun kurutma sürelerine ihtiyaç duyulmasıdır. Ancak, kömürün tutuşma riskinin olmaması nedeni ile tercih edilebilecek bir yöntemdir. Bu çalışmada, karbonik film ısıtma teknolojisi ile linyit kömürü düşük sıcaklıkta kurutulmuştur. Karbonik film teknolojisinin tercih edilmesinin nedeni düşük enerji tüketimi ve düşük sıcaklık $\left(<55{ }^{0} \mathrm{C}\right)$ üretmesidir. 
Özel üretim karbonik filmlerin yüzey sıcaklıklarının $120^{\circ} \mathrm{C}^{\prime}$ ye kadar çıkabileceği belirtilmektedir. Ancak, standart olarak üretilen ve 1 sıtma amaçlı kullanımı yaygın olan karbonik filmlerin yüzey sıcaklıkları $50-55^{\circ} \mathrm{C}^{\prime}$ lik sıcaklıkla sınırlıdır. Bu çalışmada, standart RexVa marka bir karbonik film kullanılmış ve Akdeniz Bölgesinde faaliyet gösteren bir kömür işletmesinin linyit kömürleri kurutulmuştur. Söz konusu işletmeden üretilen kömürler mevsimsel yağışa bağlı olarak \%45-55 aralığında nem içeriğine sahip olabilmektedir. Üretilen kömürler bir bant konveyör hattı ile termik santrale gönderilmekte ve $-10 \mathrm{~mm}$ tane boyutuna kırılarak akışkan yataklı bir kazanda yakılarak elektrik enerjisine dönüştürülmektedir. Bu kazanda yakılabilecek kömürün nem içeriği maksimum \%45 olmalıdır. Amaç, \%45 nem içeriğine sahip kömürü elde edebilmektir. Deneysel çalışmalarda kullanılan kömür numunesinin nem içeriği \%51.81 bulunmuştur. O halde, gerekli yakıtın eldesi için minimum \%7'lik bir nem gideriminin sağlanması gerekir.

Söz konusu kömür numunesinin karbonik film ile 1 saat kurutulması durumunda, nem içeriği \%9.01 azalmış ve nem değeri $\% 42.80$ 'e düşmüştür. 1 ton kömürden $\% 9.01$ nem giderimi için karbonik film teknolojisinin harcayacağ 1 güç $50 \mathrm{kWh}$ bulunmuştur. Ancak, bu değer teorik oranlama hesabiyla bulunduğu için gerçek uygulamada daha yüksek olabilir. Çünkü daha fazla suyun buharlaşması durumunda, kurutucu içerisinde daha büyük negatif buhar basınçları oluşturmaya ihtiyaç duyulacaktır.

Sanayi için elektrik birim fiyatının $0.41 \mathrm{TL} / \mathrm{kWh}$ olduğu kabul edilirse, 1 ton kömürün kurutulma maliyeti, karbonik film teknolojisi ile 20.5 TL bulunur. Bu rakamlar, karbonik filmin üzerinde $10 \mathrm{~mm}$ yüksekliğinde kömür kurutulduğu zaman geçerlidir. Kömür yüksekliği arttırıldığında, kurutma verimi düşmekte ve kurutma maliyeti de artmaktadır.

Karbonik filmle kurutma teknolojisinde, film üzerine konulan kömürün yüksekliği önemli bir işletim parametresidir ve bu çalışmanın bir sonucu olarak bu yüksekliğin $10 \mathrm{~mm}$ 'den daha büyük olmaması önerilir.

Deneysel çalışmalar göstermiştir ki, karbonik filmin $0.1 \mathrm{~m}^{2}$, sinde 600 gr kömür etkin olarak kurutulabildiğine göre, $1 \mathrm{~m}^{2}$ lik karbonik filmde $6 \mathrm{~kg}$ kömür kurutulabilir. 1 ton kömürün kurutulması için gerekli olan karbonik film alanı ise $166.66 \mathrm{~m}^{2}$ 'dir. Karbonik filmin $1 \mathrm{~m}^{2}$ 'si güncel fiyatlarla 3 USD'dir. Dolayısıyla sadece bu filmin maliyeti beher tor kömürün kurutması için 3 USD x166.66=499.98 USD'dir. Ancak bu fiyat; sadece klasik karbonik filmin (düşük sağlamlık ve düşük ısı üreten) maliyetidir. Kömür kurutma için kullanılacak olan karbonik filmin daha yüksek ısı üretmesi ve yüzeyinin de daha sağlam olması beklenir. Çünkü, endüstriyel kurutmalarda daha yüksek aşınmalar meydana gelecek ve daha yüksek sıcaklıklara $\left(75-100{ }^{\circ} \mathrm{C}\right)$ ihtiyaç duyulacaktır. Dolayısıyla özel tip film maliyetinin de en az $\% 25$ oranında artacağı tahmin edilmektedir. Henüz böyle bir uygulama olmadığı için tam maliyet analizi yapılamamışır.

Karbonik filmin en önemli dezavantajı muntazam kurutma yapamamasıdır. Karbonik film, sıcak yüzeyi ile temas sonucunda kurutma yapmaktadır. Dolayısıyla kömürün alt kısımları, üst kısımlarına göre daha nemli kalmaktadır. Bu durum özellikle yüksek tabaka kalınlıklarında daha da belirgin hale gelmektedir. Dolayısıyla, kurutma sonucu elde edilecek ürünün alt-üst edilerek karıştırılması gerekir, ya da kurutucu bünyesine alt-üst etme mekanizması ilave edilebilir. Bu sorun hafif titreşim ve çentikli bant konveyör kullanımı ile kısmen çözülebilmiştir. Aksi durumda üst kısımların nem içeriği, alttaki kömüre göre daha yüksek olacaktır.

Karbonik film teknolojisi, mevcut ısı üretme kapasitesi ve yapısal dayanıklılı̆̆ı ile henüz kömür sektörünün kurutma ihtiyacını karşılayabilecek gibi gözükmemektedir. Ancak; filmin yüzey sıcaklığı ve yüzey dayanıklılı̆̆ı arttırılırsa, tasarlanacak olan yeni tip karbonik filmli kurutucularla oldukça ekonomik bir kurutma yapılabilir. Bu çalışmada, karbonik filmlerin bir kurutucu olarak nasıl kullanılabileceği gösterilmiş, işletimi ve kullanımı kolay olan ekonomik yeni bir kurutucu tasarımı sunulmuştur.

\section{Teșekkür}

Bu çalışmayı, İstanbul Üniversitesi-Cerrahpaşa Bilimsel Araştırma Projeleri Koordinasyon Birimi desteklemiş̧ir. Proje numarası 33221.

\section{Kaynaklar}

[1] Karthikeyan M, Zhonghua W, Mujumdar, AS. Low-Rank Coal Drying Technologies-Current Status and New Developments, Drying Technology 2009; 27: 403-415.

[2] Yuan L, Smith AC. The Effect of Ventilation on Spontaneous Heating of Coal, Journal of Loss Prevention in the Process Industries 2012; 25: 131-137.

[3] Li Z, Zhang, Y, Jiang X, Zhang Y, Chang, L. Insight into the Intrinsic Reaction of Brown Coal Oxidation at Low Temperature: Differential Scanning Calorimetry Study, Fuel Processing Technology 2016; 147: 64-70.

[4] Qi G, Wang D, Zheng K, Xu J, Qi X, Zhong X. Kinetics characteristics of Coal Low-temperature 
Oxidation in Oxygen-depleted Air, Journal of Loss Prevention in the Process Industries 2015; 35: 224-231.

[5] Kowalski S.J, Rajewska K. Convective Drying Enhanced with Microwave and Infrared Radiation, Drying Technology 2009; 27 (7-8): 878-887.

[6] Riadh M.H, Ahmad S.A.B, Marhaban M.H, Soh A.C. Infrared Heating in Food Drying: An Overview, Drying Technology 2015; 33 (3): 322-335.

[7] Delele M.A., Weiglera, F, Mellmann J. Advances in the application of a rotary dryer for drying of agricultural products: A Review, Drying Technology 2015; 33(5): 541-558.

[8] Hacifazlioglu H. Madencilik Endüstrisinde Kurutma İşlemi ve Alternatif Kurutucu Tiplerinin Tanıtılması, MT Bilimsel Yeraltı Kaynakları Dergisi, 2019; 1-20.

[9] Hacifazlioğlu H. Production of Merchantable Coal from Low Rank Lignite Coal by Using FGX and Subsequent IR Drying, International Journal of Coal Preparation and Utilization, 2019; 38: 1-8.

[10] Jangam S.V, Majumdar A.S. Coal Dehydration, A Compilation of Relevant Publications and Technical Reports 2010; 77.

[11] Tahmasebi A, Yu J, Li X, Meesri C. Experimental study on microwave drying of Chinese and Indonesian low-rank coals, Fuel Processing Technology 2011; 92:1821-1829.

[12] Yüce İ. Uzak Kızılötesi Işıı Yayan Kumaş ve İplikler, Trakya University Journal of Engineering Sciences 2017; 18(2): 145-151.

[13] Anon, http://www.rexva.co.kr/eng/carbon-film-underfloor-heating.php?ckattempt=1, 2020. 